\title{
A Comparison of Twig-length and Browsed-
}

twig Methods of Determining Browse Utili-

\section{zation}

\section{CHARLES H. JENSEN AND GEORGE W. SCOTTER}

Highlight: Utilization of shrubs has been determined by several techniques, two of which are: (1) measuring twig lengths before and after use then calculating the percentage and (2) estimating the percentage of browsed twigs. Estimates were checked for accuracy by actually counting the number of browsed and unbrowsed twigs and then calculating percentages. The two methods were compared on a big game winter range in southcentral Utah to evaluate the agreement among utilization estimates, consistency among individual observers, and efficiency.

Estimating the percentage of browsed twigs or calculating percentages from counts of browsed and unbrowsed twigs provided higher utilization values than measuring twig lengths. Disadvantages of estimating percentages of browsed twigs include the introduction of individual bias when estimates are made and lack of sensitivity in accurately determining percentage utilization under heavy use. By contrast, calculating percentages of utilization from twig length measurements provided equal sensitivity throughout the 0 to $100 \%$ range. Twig measurement data were more consistent among observers than estimates. Measuring twig lengths required about four times as many man-hours as estimating percentages of browsed twigs or counting twig numbers.

Determining percentage utilization of key browse species is considered essential for effective big game management. A commonly used method for determining utilization of browse plants is to calculate the percentage from differences between twig lengths before and after use. This method, first suggested by Nelson (1930), became a widespread game management tool as described by Aldous (1945) and is currently employed in Utah with modifications suggested by Smith and Urness (1962). This method consists basically of selecting a series of browse plants and marking a major branch on each plant, then measuring lengths of current year's twigs in the fall and residual lengths

Authors are wildlife resources biologist, Utah Division of Wildlife Resources, Logan 84322; and research scientist, Canadian Wildlife Service, Edmonton, Alberta T5J IS6. Scotter was formerly assistant professor, Department of Range Science, Utah State University; and Federal Aid Project Leader, Utah State Division of Fish and Game.

The study is a partial contribution of PRW-105-R.

Manuscript received March 10, 1976. of those same twigs in the spring, then calculating the percentage utilization. The length removed is closely correlated with weight removed (Smith and Umess 1962).

Percentage utilization can also be determined either by estimating the percentage of twigs browsed or these estimates can be checked by counting the number of browsed and unbrowsed twigs and calculating the percentage of twigs utilized (Cole 1963). Only the number of browsed twigs is considered for this percentage, not the volume or length removed. Estimates of utilization for each plant are assigned to one of six utilization classes: $0,1-9,10-39,40-59,60-89$, $90-100$. It requires just one visit to the range, after winter use is complete.

Shrubs are selected by the "closest plant" sampling technique (Cole 1963). In using the procedure, age class and form class are assigned to each shrub, hopefully to provide estimates of range condition, and are similar to those suggested by Dasmann (1951). Although they are integral parts of the procedure outlined by Cole (1963), their utility is not restricted to a specific method of utilization determination; and they could be incorporated into any program for determining utilization. The purpose of this study was to compare the advantages and disadvantages of the two methods, but primarily the utility of each for estimating utilization.

\section{Methods}

Utilization of two browse species by mule deer in winter was determined by two methods during two different years. Percentage utilization was estimated by (1) twig length differences, and (2) estimates of the percentage of twigs browsed. The numbers of total and browsed twigs were also tallied to provide a check on estimates of the percentage of twigs browsed. The lengths of current year's twigs were measured on 150 permanently marked cliffrose (Cowania stansburiana) branches and 50 marked bitterbrush (Purshia tridentata) branches in the fall of 1967. In the spring of 1968, the residual lengths of twigs were measured on the tagged branches by four teams of observers $(2 /$ team). The plants with tagged branches were flagged with plastic tape before the methods were applied to facilitate locating 
the marked plants to minimize bias favoring one or the other method. The time required to complete the observations was recorded by each observer using the browsed-twig method and each team using the twig length method. Current year's twigs were measured between the tags and the tips of the branches and dot tallied in inch classes. Total number of twigs was obtained from dot tallies of the fall measurement data and percentage of length utilized was computed from the fall and spring measurements. After the teams completed length measurements, the unbrowsed twigs were counted by one observer and the percentage of twigs browsed was individually estimated by 7 observers on the 150 tagged cliffrose branches and 5 observers on the 50 bitterbrush branches. Variability of the estimates of percentage utilization was compared for the observers on the two species.

In addition to observations of marked branches, 3 observers estimated the percentage of twigs browsed on 50 different bitterbrush plants and 3 others on 50 different cliffrose plants in the spring of 1968, each using the "closest plant" sampling technique to determine the time required to employ that method.

Percentage utilization by length differences was determined on 120 tagged cliffrose branches and tallies of total and browsed twigs in the early winter of 1973-74 to better establish the relationship of percentage utilization values obtained in the two ways. Data were recorded at about three-week intervals. In that way, estimates of utilization could be attained when mean utilization was light as well as when it was heavy. Correlation and regression analyses were computed for the three sets of data.

\section{Results}

Mean estimated values of utilization were highest when the percentage of twigs browsed was estimated, slightly lower when the number of browsed and unbrowsed twigs were counted, and substantially lower when the length of current year's twigs was measured fall and spring. Under heavy deer use in the winter of 1967-68, the disparity between estimating the number of twigs browsed (estimates) and computing percentages from the counted number of browsed and unbrowsed twigs (counts) was 3\% for cliffrose and $8 \%$ for bitterbrush (Table 1). The disparity between estimating the number of twigs browsed and percentages calculated from before-and-after browsing twig length measurements (measurements) was $29 \%$ for cliffrose and $32 \%$ for bitterbrush. The differences between measurements and counts were $26 \%$ and $24 \%$, respectively.

The percentage of twigs browsed was not estimated in the fall and early winter of 1973-74, but the percentage difference in utilization values between browsed twig counts and length measurements demonstrated a relationship similar to that of 1968-69. By December 5, 1973, mean utilization of the twigs on 120 marked branches was $42 \%$ and $22 \%$ by counts and twig measurements, respectively, a difference of $20 \%$. By December 28 , these respective mean percentage values had increased to $89 \%$ and $62 \%$, a difference of $27 \%$.

Since the percentage of twig length removed closely approximates the percentage of twig weight removed (Smith and Urness 1962), counting the numbers of browsed and unbrowsed twigs overestimated the volume utilized by as much as $27 \%$, and

Table 1. Average utilization (\%) as determined from twig length measurements, estimated and counted numbers of browsed twigs.

\begin{tabular}{|c|c|c|c|c|}
\hline \multirow{2}{*}{$\begin{array}{l}\text { Plant } \\
\text { species }\end{array}$} & \multirow[b]{2}{*}{ Year } & \multicolumn{2}{|c|}{ Browsed twigs } & \multirow{2}{*}{$\begin{array}{l}\text { Twig length } \\
\text { difference }\end{array}$} \\
\hline & & Estimated & Counted & \\
\hline Cliffrose & $1968-69$ & 94 & 91 & 65 \\
\hline Cliffrose & Dec. 5,1973 & 1 & 42 & 22 \\
\hline Cliffrose & Dec. 28,1973 & - & 89 & 62 \\
\hline Bitterbrush & $1968-69$ & 81 & 73 & 49 \\
\hline
\end{tabular}

The percentage of twigs browsed was not estimated 1973-74. estimating the percentage of twigs browsed overestimated the volume utilized by as much as $32 \%$ (Table 1 ).

As much as $80 \%$ of the variation in percentage of twigs browsed could be accounted for by the percentage of length utilized when utilization was light, and as little as $19 \%$ when utilization was heavy (Table 2). While the coefficients of determination were low under heavy use, all differed significantly from 0 .

When utilization was light, the data fit linear, logarithmic, or quadratic regression lines fairly well (Figs. 1, 2, and 3). The

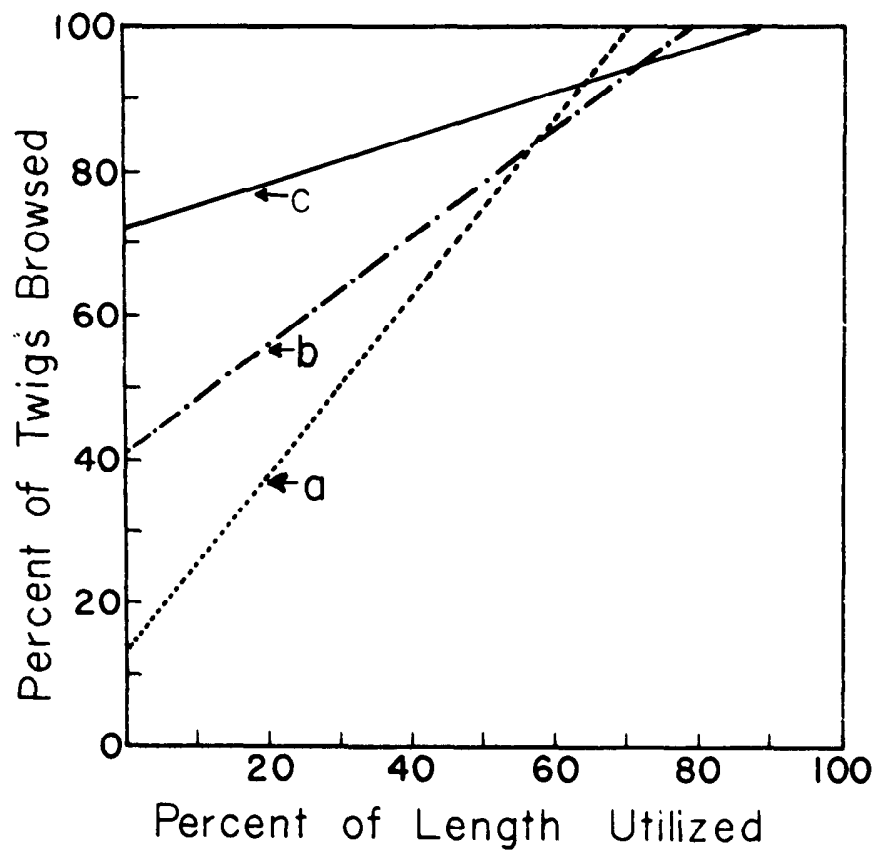

Fig. 1. Linear regression for (a) light utilization, (b) moderate utilization, and (c) heavy utilization of cliffrose by mule deer.

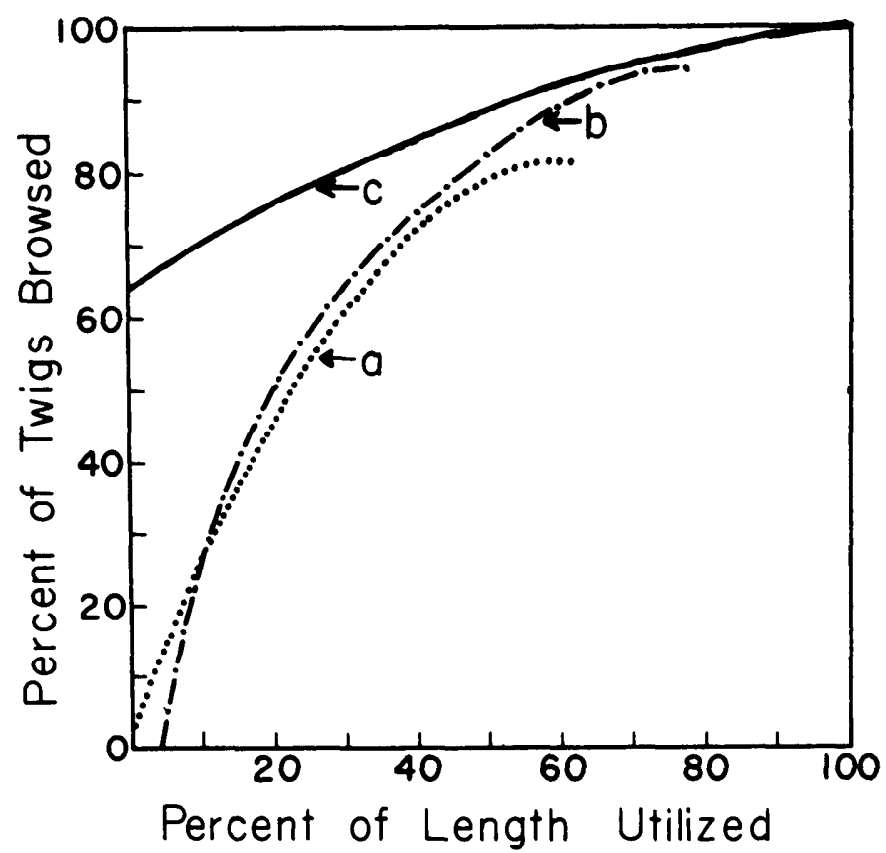

Fig. 2. Quadratic curves for (a) light utilization, (b) moderate utilization, and (c) heavy utilization of cliffrose by mule deer. 


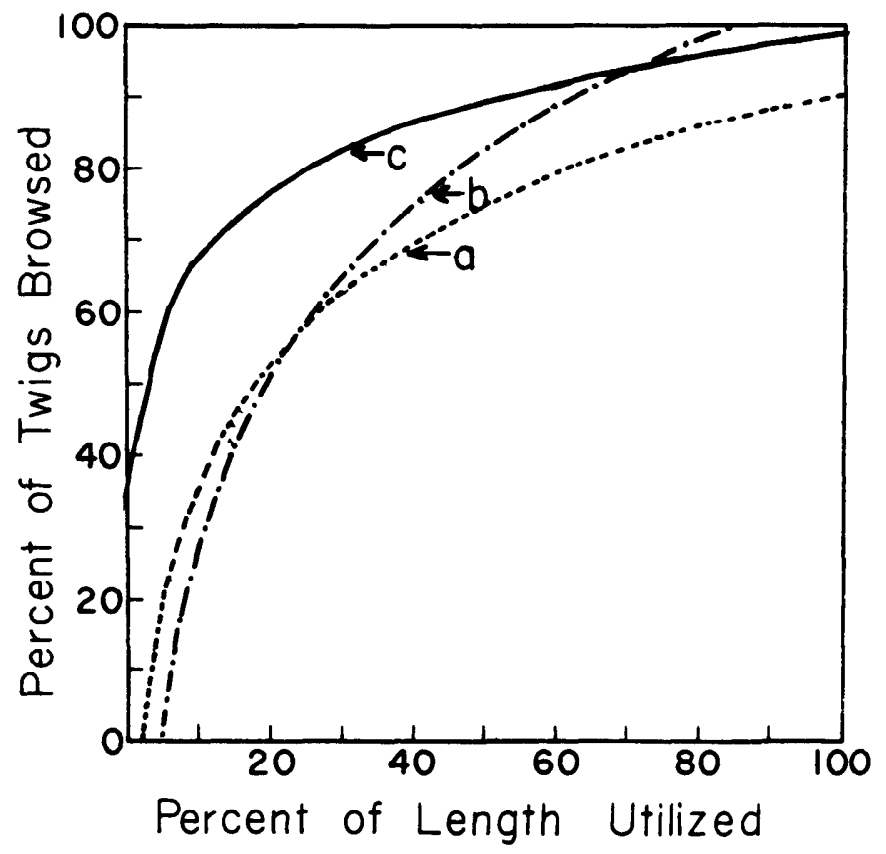

Fig. 3. Common logarithmic curves in relation to (a) light utilization, (b) moderate utilization, and (c) heavy utilization of cliffrose by mule deer.

quadratic curve provided a slightly better fit of the data than logarithmic or linear curves. The low coefficients of determination under heavy use were caused partially by the small number of twigs on tagged branches. Many branches had $100 \%$ of the twigs browsed, but utilization of length was highly variable on those branches and usually less than $100 \%$. By combining data of plants from specific sites, thereby increasing number of twigs per sample to 50 or more, values were increased to .90 , .87 , and .97 for linear, common logarithmic, and quadratic curves respectively (Fig. 4).

The estimated number of twigs browsed obtained by application of the "closest plant" technique provided utilization values comparable to estimated percentage of browsed twigs on the permanent transects in 1969 (Table 3).

Utilization values obtained by the four teams were more consistent than estimates made by individuals. The range of percentage utilization based on twig length measurements was $1 \%$ for cliffrose and 3\% for bitterbrush (Table 3). Analysis of variance provided no detectable difference at the .01 level among teams. The four teams usually reported total twig lengths within \pm 2 inches of one another on cach tagged branch. A few measurements of tagged branches varied by up to 19 inches. In such cases, one or more of the twoman teams failed to measure all twigs on the tagged branch or they measured some twigs not within the tagged portion. However, these obvious errors accounted for less than the

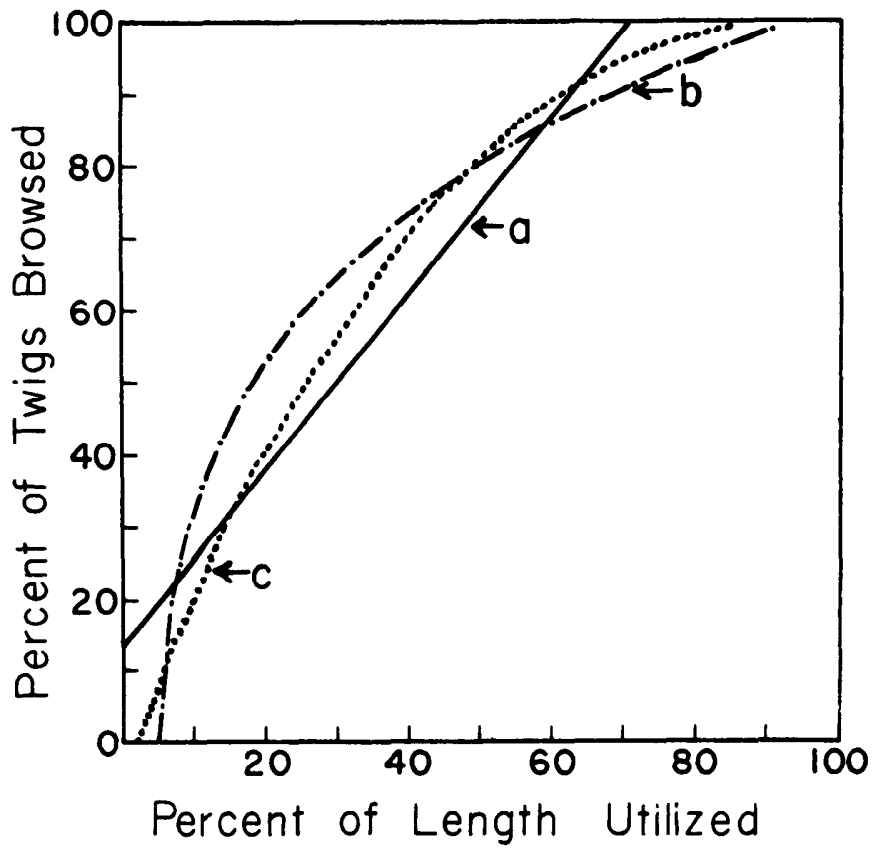

Fig. 4. A comparison of (a) linear, (b) common logarithmic, and (c) quadratic curves for combined site utilization data.

reported 3\% difference in mean percentages among teams. Individual bias was not detected in the twig-length measurement data.

The range of averages for five observers for bitterbrush and for seven estimators on cliffrose estimating the number of twigs browsed was $10 \%$. One man's estimates of percentage of browsed twigs were consistently higher than all others and another's were consistently lower, which demonstrated the tendency for individual bias in estimation.

When estimating the number of twigs browsed to the nearest $5 \%$, some wide variations occurred between estimators. Considering the proposed use classes with midpoints at $0,5,25,50$, 75 , and $95 \%$ of twigs browsed, about one-half the estimates were within the same use class. Most of the remainder fell within two use classes, but a few fell into a third use class. Estimates that ranged over three use classes varied in excess of $40 \%$. Analysis of variance showed such differences significant at the .05 level.

The time required to estimate the percentage of twigs browsed and assign appropriate form and age classes on the permanent transects ranged from 50 to 95 minutes. As observers gained experience, they required less time to estimate and record utilization on 50 permanently marked plants. Each observer completed evaluation of 50 plants on the "closest plant" transects in about 45 minutes.

Two-man teams required about 40 minutes to measure twig

Table 2. Comparison of linear, common logarithmic, and quadratic regression analysis of three sets of cliffrose utilization data plotting percentage of twigs browsed on percentage of length utilized.

\begin{tabular}{|c|c|c|c|c|c|c|c|c|c|c|c|c|c|}
\hline \multirow{2}{*}{$\begin{array}{c}\text { Sites of } \\
\text { utilization } \\
\text { data }\end{array}$} & \multirow[b]{2}{*}{ d.f. } & \multicolumn{2}{|c|}{ Means } & \multicolumn{3}{|c|}{$\begin{array}{c}\mathrm{Y}=\mathrm{a}+\mathrm{bX} \\
\text { Linear }\end{array}$} & \multicolumn{3}{|c|}{$\begin{array}{c}\mathrm{Y}=\mathrm{a}+\mathrm{b} \log \mathrm{X} \\
\text { Common } \log \end{array}$} & \multicolumn{4}{|c|}{ 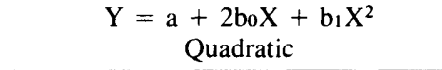 } \\
\hline & & $\bar{x}$ & $\bar{y}$ & a & b & $r^{2}$ & a & b & $r^{2}$ & $\mathrm{a}$ & bo & $b_{1}$ & $\mathrm{r}^{2}$ \\
\hline Heavy & 194 & 60.0 & 91.2 & 72.56 & 0.31 & .21 & 36.93 & 30.96 & .19 & 65.74 & 0.58 & -.0024 & .22 \\
\hline Light & 117 & 29.7 & 51.7 & 15.79 & 1.21 & .72 & 20.39 & 56.05 & .78 & 3.22 & 2.56 & -.0208 & .80 \\
\hline Moderate & 117 & 62.8 & 88.8 & 40.69 & 0.76 & .48 & -50.37 & 78.19 & 60 & -0.96 & 2.48 & -.0160 & .62 \\
\hline
\end{tabular}


Table 3. Comparison of consistency of average between observers on a bitterbrush transect and three cliffrose transects for the winter of 196869.

\begin{tabular}{|c|c|c|c|c|c|c|}
\hline \multirow[b]{3}{*}{ Species } & \multicolumn{4}{|c|}{ Estimated percentage of browsed twigs } & \multirow{2}{*}{\multicolumn{2}{|c|}{$\begin{array}{l}\text { Percentage of twig } \\
\text { length utilized on } \\
\text { permanent transect }\end{array}$}} \\
\hline & \multicolumn{2}{|c|}{ "Closest plant", } & \multicolumn{2}{|c|}{ Permanent transect } & & \\
\hline & $\begin{array}{c}\text { No. of } \\
\text { observers }\end{array}$ & Range & $\begin{array}{c}\text { No. of } \\
\text { observers }\end{array}$ & Range & $\begin{array}{l}\text { No. of } \\
\text { teams }\end{array}$ & Range \\
\hline Bitterbrush & 3 & 7 & 5 & $\Delta$ & 4 & $48-51$ \\
\hline Cliffrose & 3 & 94-95 & 7 & $87-97$ & 4 & $61-62$ \\
\hline
\end{tabular}

lengths of the 50 tagged cliffrose branches and about 50 minutes to measure twig lengths of the 50 tagged bitterbrush branches, about twice as many man-hours as estimating the number of twigs browsed. Combining the time required for fall measurements with that required for spring measurements, the twig length method takes about four times as long as the browsedtwig method.

\section{Discussion}

Neither estimating the number of twigs browsed nor measuring twig lengths supplies the ultimate data for managing big game herds on winter ranges. Estimating the number of twigs browsed requires only one technician to collect and record the information. However, individual biases influence estimated values. It also becomes insensitive under heavy utilization levels. Stickney (1966) found this to be true at utilization levels above 55\% of length for black chokecherry (Prunus virginiana) and about $60 \%$ of length for Saskatoon serviceberry (Amelanchier alnifolia). Similar results have been reported for several herbaceous species (Springfield 1961; Springfield and Peterson 1964; and Charlton 1968).

Obtaining useful utilization data from numbers of twigs browsed is further diminished when considering proper or allowable utilization levels. Evidence has demonstrated that utilization intensities exceeding $60 \%$ of the twig length may be permissible for some species in Oregon (Garrison 1953). Garrison (1953) found that foliage production of bitterbrush and nubber rabbitbrush (Chrysothamnus nauseosus) could be increased on some sites by $75 \%$ clipping intensities. If removal of $50 \%$ or more of the average twig length is considered proper use or if utilization exceeds $60 \%$, which it frequently does, a technique must be employed that will precisely measure that utilization. Counting the number of browsed and unbrowsed twigs or estimating the percentage of twigs browsed fails to do this.

The twig-length method does not provide a measure of condition or trend as it is presently employed. It is designed to measure utilization and does this with comparatively high precision. When an objective scale such as length measurements is employed, little bias will be introduced by observers. Therefore, annual utilization determinations should be comparable, even though observers may change. Average twig length provides a comparable index of forage yield from year to year, an important consideration when recommending hunting seasons. If yield of available forage has decreased from the previous year, for example, utilization by a static animal population should be expected to increase and vice versa although this may not always be so. The problem of arriving at yield indexes from current average twig length has been recognized and discussed by Dasmann and Hjersman (1958) and Smith and Urness (1962).

\section{Conclusion}

Techniques that depend upon the numbers of browsed twigs, without regard to weight consumed, are generally restricted to establishing utilization at levels less than $60 \%$ of the weight. Such methods may be suited to certain situations. If final utilization is expected to be light or when periodic checks are needed to insure that utilization does not exceed $40-50 \%$, more laborious procedures need not be considered. The real advantages of "counting" methods are speed and simplicity (Stoddart 1935). If stems are completely removed with first contact by an animal, the relationship between numbers and volume is linear and certainly the most rapid method is the best in this case. However, such situations rarely occur, and if not, the results are unreliable (Pechanec 1935).

The main problem in estimating or counting the number of twigs browsed lies in its inability to provide adequate information for managers. For example, managers will generally allow $50-60 \%$ utilization by weight of a key plant species. Frequently, removal exceeds $50 \%$ of the key species on big game winter ranges, but counting or estimating numbers of twigs browsed cannot detect this adequately. For that reason, it is important to use a technique that will measure volume removed precisely from $0-100 \%$ when utilization data are essential to proper management. The twig length method fulfills this requirement.

\section{Literature Cited}

Aldous, C. M. 1945. A winter study of mule deer in Nevada. J. Wildl Manage. 9:145-151

Charlton, M. 1968. Grazed plant utilization method. J. Range Manage. 21: 334-335

Cole, G. F. 1963. Range survey guide. Printed by Grand Teton Nat. Hist. Ass Nat. Park Serv., Dep. of the Interior. $22 \mathrm{p}$.

Dasmann, W. P. 1951. Some deer range survey methods. California Fish and Game. 37:43-52.

Dasmann, W. P., and H. A. Hjersman. 1958. Deer survival and range forage trends on eastern California winter ranges. California Fish and Game. 44: $51-72$.

Garrison, G. A. 1953. Effects of clipping on some range shrubs. J. Range Manage. 6:309-317.

Nelson, E. W. 1930. Methods of studying shrubby plants in relation to grazing Ecology 11:764-769.

Pechanec, J. F. 1936. Comments on the stem-count method of determining the percentage utilization of ranges. Ecology 17:329-331.

Smith, A. D., and P. J. Urness. 1962. Analyses of the twig length method of determining utilization of browse. Utah Div. Fish and Game Bull., 62-9.34p.

Springfield, H. W. 1961. The grazed plant method for judging the utilization of crested wheatgrass. J. Forest. 59:666-670.

Springfield, H. W., and G. Peterson. 1964. Use of the grazed plant method for estimating utilization of some range grasses in New Mexico. U.S. Forest Serv. Res. Note RM-22. 6 p.

Stickney, P. F. 1966. Browse utilization based on percentage of twig numbers grazed. J. Wildl. Manage. 30:204-206.

Stoddard, L. A. 1935. Range capacity determination. Ecology 16:531-533 